\title{
Iron absorption from infant formula and iron-fortified cow's milk: experimental model in weanling rats
}

\author{
Mariana de L. Costa, ${ }^{1}$ Karine de C. Freitas, ${ }^{2}$ Olga M. S. Amancio, ${ }^{3}$ \\ Ângela T. Paes, ${ }^{4}$ Sylvia M. A. da Silva, ${ }^{5}$ Jacqueline Luz, $^{6}$ Mauro B. de Morais ${ }^{7}$
}

\begin{abstract}
Objective: To compare iron absorption from infant formula and iron-fortified cow's milk.

Methods: Twenty-four weanling Wistar rats were maintained in metabolic cages during the whole experiment (10 days). On the first day, the animals were divided into three similar groups according to their weight, length, hematocrit and hemoglobin levels: 1 ) infant formula; 2) powdered whole cow's milk fortified with iron in the same quantity and type as the formula; 3 ) control - powdered whole cow's milk not fortified with iron. Deionized water and diet were offered ad libitum, and the volume consumed was measured. Weight, hematocrit, and hemoglobin levels were measured on the fifth and 10th days when length, fecal occult blood, and hepatic iron levels were also analyzed.

Results: Group 1 consumed less diet $(450.5 \pm 26.50 \mathrm{~mL})$ than group $2(658.8 \pm 53.73 \mathrm{~mL})$ and control group $(532.7 \pm 19.06 \mathrm{~mL}, \mathrm{p}<0.001)$. Hemoglobin levels were higher $(\mathrm{p}<0.001)$ in group $1(12.1 \pm 1.13 \mathrm{~g} / \mathrm{dL})$ than in group $2(9.6 \pm 1.59 \mathrm{~g} / \mathrm{dL})$ and in control group $(6.2 \pm 0.97 \mathrm{~g} / \mathrm{dL})$. Hepatic iron level showed the same pattern as hemoglobin $(p<0.001)$. There was no difference in weight and length between the three groups $(p=0.342)$. There was no fecal occult blood in the any of the animals.
\end{abstract}

Conclusions: Despite the lower volume consumed, the group that received formula presented higher iron absorption and hemoglobin levels than the group fed with fortified whole cow's milk. Growth was similar in the three groups.

J Pediatr (Rio J). 2009;85(5):449-454: Breast milk substitutes, dietary iron, biological availability, iron deficiency.

\section{Introduction}

Iron deficiency anemia is the most prevalent nutritional deficiency in the world, and children younger than 2 years old are among the main risk groups for this disease. Although several factors may contribute to the development of iron deficiency anemia in infants, it is assumed that it is a result of the combination between exceptionally high needs of iron, caused by growth, and low iron-content diets, or diets with low iron bioavailability.

1. Mestre, Programa de Pós-Graduação em Pediatria e Ciências Aplicadas à Pediatria, Universidade Federal de São Paulo (UNIFESP), São Paulo, SP, Brazil.

2. Doutora, Programa de Pós-Graduação em Nutrição, UNIFESP, São Paulo, SP, Brazil.

3. Professora adjunta, Departamento de Pediatria, UNIFESP, São Paulo, SP, Brazil.

4. Estatística, Departamento de Medicina Preventiva, UNIFESP, São Paulo, SP, Brazil.

5. Técnica, Setor de Termometabologia, Departamento de Fisiologia, UNIFESP, São Paulo, SP, Brazil.

6. Professora adjunta, Departamento de Fisiologia, UNIFESP, São Paulo, SP, Brazil.

7. Professor associado, livre-docente, Departamento de Pediatria, UNIFESP, São Paulo, SP, Brazil.

This study was conducted during the Course of Pediatric Gastroenterology, Department of Pediatrics, Universidade Federal de São Paulo (UNIFESP) and at the Research Laboratory, Department of Pediatrics, UNIFESP, São Paulo, SP, Brazil.

Financial support: Coordenação de Aperfeiçoamento de Pessoal de Nível Superior (CAPES) and Fundação de Amparo à Pesquisa do Estado de São Paulo (FAPESP), Brazil.

Conflict of interest: In the present study we used infant formulas and whole cow's milk produced by the same manufacturer (Nestlé Brasil), which did not participate in the design and execution of the project and did not provide financial support.

Suggested citation: Costa ML, Freitas KC, Amancio OM, Paes AT, da Silva SM, Luz J, et al. Iron absorption from infant formula and iron-fortified cow's milk: experimental model in weanling rats. J Pediatr (Rio J). 2009;85(5):449-454.

Manuscript submitted May 4 2009, accepted for publication Jul 152009.

doi:10.2223/JPED.1953 
Exclusive breast-feeding during the first 6 months of life is the main strategy to avoid iron deficiency in this age group. ${ }^{1}$ However, only $39.8 \%$ of the children were exclusively breastfed up to the sixth month of life in Brazil in 2006. ${ }^{2}$ For the large number of infants submitted to early weaning, the use of infant milk-based formulas fortified with iron (infant formula) is one of the most appropriate alternatives to guarantee their good nutrition. ${ }^{3}$ However, due to cultural and socioeconomic factors, access and availability of these formulas are reduced, making whole cow's milk the most frequent substitute of breast milk. ${ }^{4}$

In spite of the experimental evidence suggesting that higher amounts of calcium and protein in the diet decrease iron absorption, 5-10 there are not studies assessing their effect on the amount of iron in body compartments during the first 6 months of life. Some methods have been used to asses iron bioavailability in the foods consumed by infants, mainly in vitro and in vivo techniques with adults $6,7,10,15$ and 14- or 21 -day-old rats. ${ }^{11,16}$ Nevertheless, none of the studies published in the literature has compared the difference between iron absorption from infant formulas and from fortified whole cow's milk often offered as the only source of food to weaned infants younger than 6 months, considering whole cow's milk as the most inexpensive option.

Therefore, the ethical restrictions that limit the possibility of analyzing the negative effect of the consumption of whole cow's milk during the infant's first 6 months of life and the lack of effectiveness of the measures taken to prevent iron deficiency in this population are the main reasons of this project. The objective of the present study is to compare iron absorption in weanling rats receiving infant formula with rats fed with fortified whole cow's milk containing the same quantity and type of iron as the infant formula.

\section{Methods}

Twenty-four male Wistar rats were used. The animals were 21-day-old on the first day of weaning. The experiment was divided into two phases, each one involving 12 rats. On the first day of the experiment, with the purpose of making up three similar groups, the animals were weighed and their length was measured. Their hematocrit and hemoglobin levels were also analyzed. The rats were weighed using an electronic digital scale CG-Libor L-600 (CG Instrumentos Científicos Ltda., São Paulo, Brazil), with maximum capacity of $600 \mathrm{~g}$ and sensitivity of $0.1 \mathrm{~g}$. Their length was expressed in centimeters, including the length of body and tail. Blood was collected from the rats' tail. Hematocrit and hemoglobin levels were determined using the Wintrobe ${ }^{17}$ and the cyanmethemoglobin methods, respectively.

Next, the animals were kept in individual metabolic cages (Nalgene Metabolic Cages 650-0100, Tecniplast, Buguggiate, Italy) under a 12-hour light cycle and at a temperature of $23 \pm 1^{\circ} \mathrm{C}$. Two drinking fountains previously treated with nitric acid and rinsed with deionized water were installed in each cage. The animals allocated in group $1(n=8)$ were fed with infant formula; those allocated in group $2(n=8)$ received fortified powdered whole cow's milk with the same amount and type of iron as the infant formula; and those in the control group $(n=8)$ were fed with powdered whole cow's milk not fortified with iron. The control group was formed with the purpose of validating the experimental model. All diets were prepared according to the recommendations of the manufacturer, and their nutritional composition is described in Table 1.

During the whole experiment (10 consecutive days), the animals received deionized water ad libitum using the MilliQ Plus system (Millipore Indústria e Comércio Ltda., Barueri, Brazil) and the same volume of liquid milk diet $(150 \mathrm{~mL})$ divided into three meals a day. The volumes consumed were measured. The drinking fountains were cleaned every time the water and diet were replaced.

On the third day of the experiment, 24-hour-diuresis was collected, after being measured, urine was placed in microtubes (Eppendorf do Brasil Ltda., São Paulo, Brazil)

Table 1 - Nutritional composition of diets offered in the experiment

\begin{tabular}{lccc}
\hline $\mathbf{1 0 0}$ mL of diet & $\begin{array}{c}\text { Infant } \\
\text { formula }\end{array}$ & $\begin{array}{c}\text { Fortified } \\
\text { cow's milk }\end{array}$ & $\begin{array}{c}\text { Unfortified } \\
\text { cow's milk }\end{array}$ \\
\hline Energy (kcal) & 74.39 & 74.31 & 74.31 \\
Carbohydrate (g) & 8.31 & 5.0 & 5.0 \\
Lipid (g) & 4.01 & $4.58^{*}$ & $4.58^{*}$ \\
Protein (g) & 1.36 & 3.25 & 3.25 \\
Vitamin C (mg) & 7.45 & 125.5 & + \\
Calcium (mg) & 45.87 & 43.5 & 425.5 \\
Sodium (mg) & 17.2 & $0.89^{\ddagger}$ & + \\
Iron (mg) & 0.89 & & \\
\hline
\end{tabular}

* 0.98 of vegetable oil.

$\dagger$ Insignificant value considering the volume of diet offered.

$\ddagger 0.89 \mathrm{mg}$ of iron in the form of ferrous sulphate. 
and froze at $-20^{\circ} \mathrm{C}$. Urine tests determined creatinine, sodium, and urea levels (Bayer ADVIA 1650, Bayer S.A., São Paulo, Brazil).

On the fifth day, the rats' body weight was measured, and hemoglobin and hematocrit levels were determined. These procedures were carried out again on the 10th day, and the animals' length was also measured. Fecal occult blood was investigated in four animals of each group using the Hemoplus kit (Newprov - Produtos para Laboratórios Ltda., Pinhais, Brazil) only during the second phase of the experiment.

The animals were previously anesthetized using isoflurane inhalation and were sacrificed by vena cava exsanguination. The animals were sacrificed between 6 and 10 am. ${ }^{18} \mathrm{pH}$ of the cecal content was directly analyzed in the cecum inserting the combined electrode DME-CF1 attached to the pH meter DM-22 (Digimed, São Paulo, Brazil).

The kidneys and the liver of each animal were immediately extracted and weighed (fresh weight) using an analytical scale Mettler AB204 (Mettler Toledo Indústria e Comércio Ltda., Barueri, Brazil) with maximum capacity of $200 \mathrm{~g}$ and sensitivity of $0.1 \mathrm{mg}$. After being weighed, the kidneys were discarded and the livers were stored at $-20{ }^{\circ} \mathrm{C}$ for later analysis of hepatic iron levels. With that purpose, the livers were dried in a stove at $120{ }^{\circ} \mathrm{C}$ for 22 hours; next, their dry weight was measured. The dry livers were ground, and the hepatic iron level was determined using an atomic absorption spectrophotometer Perkin Elmer 5100 (PerkinElmer do Brasil Ltda., São Paulo, Brazil).

The animals were eviscerated by separating the several parts of the carcass made up of fur, skin, subcutaneous fat, muscles, bones, teeth, and nails. Carcasses were weighed using a digital electronic scale to determine their fresh weight and homogenized and stored in a freezer for later analysis of the amount of body water, fat, and protein. A sample of $0.1 \mathrm{~g}$ of the homogenized material was used to establish total protein level using the Lowry's method, 19 and a sample of $2.0 \mathrm{~g}$ was used to determine fat content using the chloroform-methanol method. ${ }^{20}$ Both these tests were carried out twice. After these procedures, the fresh homogenized carcass was placed in a stove FANEM 315 SE (FANEM Ltda., São Paulo, Brazil) at $60^{\circ} \mathrm{C}$ for 1 week. Then dry weight was measured, which was corrected according to the amount of the previously extracted sample. The percentage of body water was calculated based on the difference between the fresh weight and dry weight of the carcass.

The parametric variables were expressed as mean and standard deviation, and the nonparametric variables were expressed as median and 25th and 75th percentiles. Students $t$ test and the analysis of variance or the KruskalWallis analysis of variance were used to compare the independent groups according to the distribution of variables.
Tukey or Scheffe's multiple comparison tests were used whenever necessary. Calculations were carried out using the computer program for statistical analysis SPSS version 11.0 for Windows, adopting a significance level of the null hypothesis of $5.0 \%$.

The study protocol was approved by the Research Ethics Committee of Universidade Federal de São Paulo (UNIFESP), CEP 0478/07, São Paulo, Brazil.

\section{Results}

Before offering experimental diets to the animals, we did not find any significant statistical difference between the groups fed with infant formula $(n=7)$, iron-fortified whole cow's milk $(n=8)$ or unfortified cow's milk $(n=7)$ in terms of weight $(49.2 \pm 5.1$ vs. $48.5 \pm 2.8$ vs. $47.8 \pm 4.7 \mathrm{~g}$; $\mathrm{p}=0.820)$, length $(19.6 \pm 0.7$ vs. $19.7 \pm 0.6$ vs. $19.3 \pm 0.9$ $\mathrm{cm} ; \mathrm{p}=0.497)$, hemoglobin ( $8.8 \pm 0.5$ vs. $9.1 \pm 0.8$ vs. $9.0 \pm 0.5 \mathrm{~g} / \mathrm{dL} ; \mathrm{p}=0.648)$, and hematocrit (26.7 $\pm 2.7 \mathrm{vs}$. $29.6 \pm 4.7$ vs. $28.4 \pm 3.8 \% ; p=0.369$ ), evidencing that the groups had similar characteristics which were not changed after the exclusion of those animals that did not complete the whole period of investigation.

During the experiment, larger volumes of diets were consumed by the groups that received fortified whole cow's milk (658.8 $\pm 53.7 \mathrm{~mL})$ or unfortified cow's milk (532.7 $\pm 19.1 \mathrm{~mL}$ ) when compared to the volumes consumed by the group fed with infant formula $(450.5 \pm 26.5 \mathrm{~mL}$; $\mathrm{p}$ $<0.001$ ). As a consequence, the groups fed with fortified or unfortified whole cow's milk compared to the group that received infant formula had a higher intake of proteins ( $21.4 \pm 1.7$ vs. $17.3 \pm 0.6$ vs. $6.1 \pm 0.4$ g; $p<0.001)$, calcium ( $826.8 \pm 67.4$ vs. $668.6 \pm 23.9$ vs. $206.6 \pm 12.2 \mathrm{mg}$;

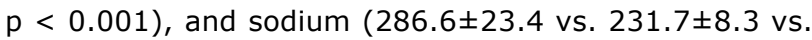
$77.5 \pm 4.6 \mathrm{mg} ; \mathrm{p}<0.001)$. The group fed with fortified whole cow's milk also consumed a larger amount of iron $(5.9 \pm 0.5 \mathrm{mg})$ in comparison with the group fed with infant formula $(4.0 \pm 0.2 \mathrm{mg} ; \mathrm{p}<0.001)$. There was no difference regarding the consumption of water between the groups that received infant formula $(33.3 \pm 13.1 \mathrm{~mL})$, fortified whole cow's milk $(26.1 \pm 11.8 \mathrm{~mL})$, or unfortified cow's milk (40.9 $\pm 16.47 \mathrm{~mL} ; \mathrm{p}=0.188)$.

There was not difference in terms of weight and length between the groups at any phase of the experiment. On the fifth day, the groups that received infant formula, fortified whole cow's milk, or unfortified cow's milk had, respectively, mean weight of $50.7 \pm 4.8,53.8 \pm 4.8$, and $56.9 \pm 5.3 \mathrm{~g}(\mathrm{p}=0.094)$. On the 10th day, these values were $60.3 \pm 6.6,68.9 \pm 13.6$ and $64.1 \pm 11.5 \mathrm{~g}(\mathrm{p}=0.342)$; while the mean length of the groups fed with infant formula, fortified whole cow's milk, or unfortified cow's milk were, respectively, $22.5 \pm 1.1,23.4 \pm 2.0$, and $23.1 \pm 1.3 \mathrm{~cm}$ $(p=0.547)$. There was not significant statistical difference regarding the feed efficiency. There was also no difference 
in the percentage of water or body levels of fat and protein in the three groups (Table 2).

Fresh weight of kidneys was similar in the three groups: infant formula $(0.9 \pm 0.1 \mathrm{~g})$, iron-fortified whole cow's milk $(0.9 \pm 0.1 \mathrm{~g})$, and unfortified cow's milk $(0.9 \pm 0.2 \mathrm{~g} ; \mathrm{p}=$ 0.342 ). There was a larger volume of diuresis in the group fed with fortified whole cow's milk in comparison with the group fed with infant formula. There was no difference in the liquid volume (water and formula, or whole cow's milk) consumed by the three groups in the 24-hour period during which diuresis was collected. The groups fed with whole cow's milk had larger volumes of sodium and urea in the urine than the group fed with infant formula. Urinary creatinine level was similar in the three groups (Table 3 ).

Since the fifth day, we found a difference between the groups fed with infant formula, fortified whole cow's milk, or unfortified cow's milk with regard to the levels of hemoglobin $(13.0 \pm 0.49$ vs. $11.6 \pm 0.58$ vs. $7.7 \pm 0.57 \mathrm{~g} / \mathrm{dL}$; $\mathrm{p}<0.001)$ and hematocrit ( $38.3 \pm 3.93$ vs. $34.1 \pm 2.69$ vs. $22.3 \pm 1.48 \% ; p<0.001)$. On the 10 th day, these differences were still present, corresponding to $12.1 \pm 1.13,9.6 \pm 1.59$, and $6.2 \pm 0.97 \mathrm{~g} / \mathrm{dL}$, for the hemoglobin values ( $\mathrm{p}<0.001)$, and $39.0 \pm 2.83,30.7 \pm 3.28$, and $18.7 \pm 2.98 \%$, for the hematocrit values $(p<0.001)$, respectively. Figure 1 shows the evolution of the mean levels ( \pm standard deviation) of hemoglobin throughout the experiment. We also found a statistically significant difference in terms of hepatic iron levels, which was higher in the group that received infant formula ( $776.7 \pm 81.4 \mu \mathrm{g} / \mathrm{g}$ ) compared with the groups that received fortified whole cow's milk $(173.0 \pm 63.78 \mu \mathrm{g} / \mathrm{g})$ or unfortified cow's milk $(99.7 \pm 13.99 \mu \mathrm{g} / \mathrm{g} ; \mathrm{p}<0.001)$. There was a difference regarding the fresh weight of the liver between the groups that received infant formula (2.6 0.3 $\mathrm{g})$, fortified whole cow's milk $(3.1 \pm 0.4 \mathrm{~g})$, or unfortified cow's milk $(2.5 \pm 0.3 \mathrm{~g} ; \mathrm{p}<0.01)$. However, this difference was not present when we analyzed the fresh weight of the liver corrected according to the animal's weight $(p=0.115)$ : $0.04 \pm 0.01,0.05 \pm 0.01$, and $0.04 \pm 0.01 \mathrm{~g}$, respectively.

$\mathrm{pH}$ of cecal content was not different between the groups fed with infant formula $(5.5 \pm 0.5)$, fortified whole cow's milk $(6.0 \pm 1.3)$, or unfortified cow's milk $(6.1 \pm 0.5 ; p=0.519)$. There was not presence of occult blood in the 12 fecal samples analyzed in the second phase of the project.

\section{Discussion}

The present study demonstrated that the consumption of iron was higher in the group fed with fortified whole cow's milk when compared with the group that received infant

Table 2 - Weight gain, feed efficiency (relation between weight gain and amount of diet consumed) and body composition of the carcasses at the end of the experiment

\begin{tabular}{lcccc}
\hline Variables & $\begin{array}{c}\text { Infant } \\
\text { formula }(\mathbf{n}=\mathbf{7})\end{array}$ & $\begin{array}{c}\text { Fortified } \\
\text { cow's milk }(\mathbf{n}=\mathbf{8})\end{array}$ & $\begin{array}{c}\text { Unfortified } \\
\text { cow's milk }(\mathbf{n}=\mathbf{7})\end{array}$ & $\mathbf{p} *$ \\
\hline Weight gain $(\mathrm{g})$ & $11.1 \pm 5.55$ & $20.4 \pm 13.48$ & $16.4 \pm 9.99$ & 0.247 \\
Feed efficiency (g/g) & $0.2 \pm 0.09$ & $0.2 \pm 0.17$ & $0.2 \pm 0.14$ & 0.576 \\
Body protein (mg/g) & $158.2 \pm 23.68$ & $150.0 \pm 25.19$ & $142.0 \pm 30.52$ & 0.532 \\
Body fat (mg/g) & $79.7 \pm 19.92$ & $74.5 \pm 14.0$ & $80.2 \pm 28.14$ & 0.842 \\
Body water (\%) & $72.2 \pm 1.24$ & $71.3 \pm 1.35^{+}$ & $71.0 \pm 1.65$ & 0.295 \\
\hline
\end{tabular}

* Analysis of variance.

$+n=7$.

Table 3 - Volume of liquid consumed, volume of 24-hour diuresis, and creatinine, sodium and urea levels in the urine

\begin{tabular}{|c|c|c|c|c|}
\hline Variables & $\begin{array}{c}\text { Infant } \\
\text { formula }(n=6)\end{array}$ & $\begin{array}{c}\text { Fortified } \\
\text { cow's milk }(n=6)\end{array}$ & $\begin{array}{c}\text { Unfortified } \\
\text { cow's milk }(n=6)\end{array}$ & p* \\
\hline Liquid intake (mL) & $30.3 \pm 4.34$ & $38.5 \pm 8.79$ & $37.6 \pm 8.50$ & 0.151 \\
\hline Volume of diuresis (mL) & $17.6 \pm 3.26^{a}$ & $23.4 \pm 2.57^{b}$ & $20.3 \pm 3.39 a b$ & 0.019 \\
\hline Sodium in the urine $(\mathrm{mmol} / \mathrm{L})$ & $12.3 \pm 2.34^{a}$ & $26.8 \pm 4.44^{b}$ & $24.3 \pm 4.76^{b}$ & $<0.001$ \\
\hline Urea in the urine $(\mathrm{mg} / \mathrm{dL})$ & $81.5^{a}(51.75-145.5)$ & $864.0^{b}(786.5-1229.0)$ & $1012.5^{\mathrm{b}}(712.25-1239.75)$ & $0.003^{+}$ \\
\hline Creatinine in the urine $(\mathrm{mg} / \mathrm{dL})$ & $6.3 \pm 1.06$ & $7.1 \pm 0.36$ & $6.9 \pm 0.82$ & 0.204 \\
\hline
\end{tabular}

* Analysis of variance.

† Kruskal-Wallis.

Variables with different letters in the same line, $p<0.05$ 

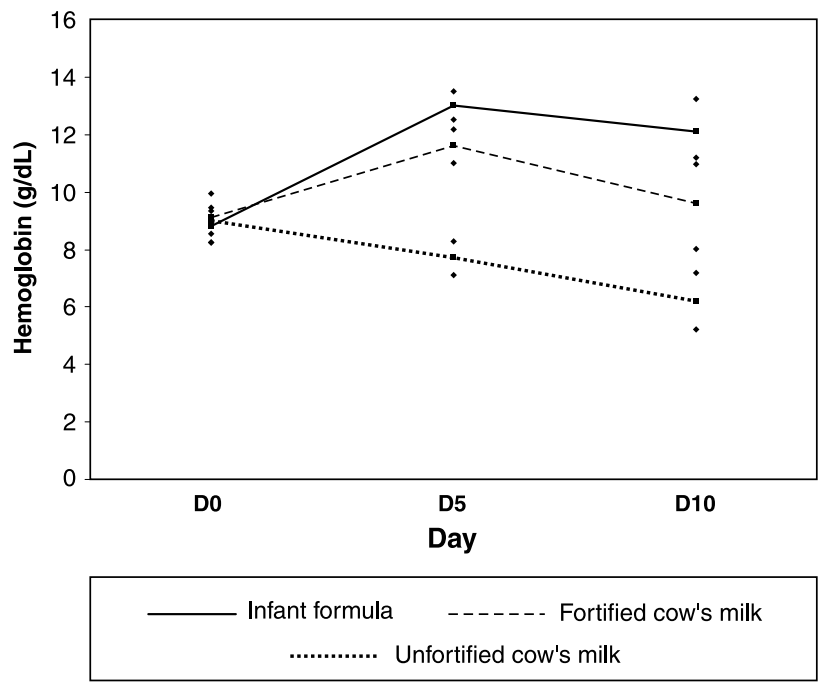

Analysis of variance for repeated measures within the same group (day 0 vs. day 5 vs. day 10):

Hemoglobin

Infant formula: $\mathrm{p}<0.001$ - Tukey's test: day $0<$ day 5 ; day $0<$ day 10 ; day $5 \approx$ day 10 .

Fortified cow's milk: $p<0.001$ - Tukey's test: day $0<$ day 5 ; day $5>$ day 10 ; day $0 \approx$ day 10

Cow's milk: $p<0.001$ - Tukey's test: day $0>$ day 5 ; day $0>$ day 10 ; day $5>$ day 10 .

Figure 1 - Evolution of the mean levels ( \pm standard deviation) of hemoglobin according to each group

formula and, evidently, when compared with the group fed with unfortified cow's milk. However, after a 10-day period of research, the group that received infant formula had a mean hemoglobin level $20.6 \%$ higher than the mean of the group that received fortified whole cow's milk. The group fed with unfortified cow's milk had a mean hemoglobin level corresponding to $64.6 \%$ of the value found in the group that received fortified whole cow's milk and $51.2 \%$ of the value found in the group that received infant formula. Hepatic iron level showed the same pattern as hemoglobin. Therefore, these findings corroborate the negative effect of the consumption of whole cow's milk on iron absorption in comparison with infant formula, which was observed on the fifth day of the experiment, evidencing depletion of the body supplies of iron regardless of the presence of iron fortification in the milk.

Few articles published in the literature about iron absorption have analyzed infant formulas or other types of milk consumed by infants. These studies have demonstrated that calcium ${ }^{5-7}$ and milk proteins ${ }^{5,10,16}$ reduce iron bioavailability, whereas other dietary factors, such as ascorbic acid, favor its absorption. ${ }^{21}$

The present study is the first to compare iron absorption from infant formula and from iron-fortified whole cow's milk for a period long enough to cause significant changes in the body compartments of this mineral. This strategy replicates the dietary regimen of children in the first 6 months of life who have their nutritional needs satisfied based only on one source of milk, when, for any reason, they are not being breastfed. Due to ethical reasons, it is almost impossible to conduct this experiment in infants younger than 6 months old.

Rats aged 14 days were used in previous studies as a model for the assessment of mineral bioavailability in infant formulas. ${ }^{11,16}$ In the present study, we used 21 -day-old rats because they have better tolerance to the diets when compared to 14-day-old rats or adult rats, as it has been observed in pilot studies carried out at our laboratory. In addition, rats' offspring have high levels of body iron at birth, which are reduced only when they are weaned, while iron absorption increases. Thus, there is better control of the regulation of iron absorption, as a response to its supplementation, in 20-day-old rats in comparison with 10-day-old rats. ${ }^{22}$

Another aspect that should be highlighted is the exclusive use of infant formula or whole cow's milk as the food offered during 10 consecutive days. In a study ${ }^{16}$ that assessed the effects of thermal processing on iron bioavailability in infant formulas (dehydrate or sterilized), 21-day-old rats were fed with a mix of freeze-dried liquid infant formula and conventional rat food. The authors did not find a negative effect of this diet on iron absorption, which occurred when the same formula was offered alone to the 14-day-old animals. ${ }^{16}$ This possibly demonstrated the influence of rat food on the iron bioavailability of the experimental diet, and this might be a bias in this study design, ${ }^{16}$ since these authors did not used milk as the exclusive source of nutrition.

Up to the fifth day of our experiment, the animals had a weight gain similar to that of rats at the same age fed with conventional rat food. On the 10th day, the mean weight of our animals corresponded to about $80 \%$ of the value expected considering this same parameter.

In spite of the higher consumption of diet and higher energy intake reached by the groups that received whole cow's milk when compared with the group fed with infant formula, there was not any difference in the weight gain between the groups. We also did not find differences in the levels of body water, fat, and protein. Feed efficiency was similar in the three groups.

The influence of high loads of electrolytes and proteins on growth and renal functioning has been previously analyzed in the literature. ${ }^{23,24}$ In rats, diets containing $12.0,21.0$ or $50.0 \%$ of protein showed increase in the weight of kidneys only in the last mentioned group. ${ }^{24}$ The percentages of protein contained in the liquid diets of the present study ( 7.3 or $17.5 \%$ in the groups that received infant formula or whole cow's milk, respectively), as expected, did not result in a difference in the weight of the kidneys. 
It is also important to highlight the significant difference in the sodium and urea levels in the urine on the third day of the experiment, thus reflecting the effects of a higher consumption of sodium and protein by the groups fed with whole cow's milk 3 days after the beginning of the dietary intervention. High renal solute load of a certain type of food requires the appropriate consumption of liquid to preserve body homeostasis. In our study, we found a larger volume of diuresis only in the group fed with fortified whole cow's milk, and there was no difference in the consumption of liquids between the three groups.

It is worth mentioning that infants may have fecal occult blood when they are fed with whole cow's milk. ${ }^{25}$ This analysis was not included in the initial part of our project. It was included in the second phase due to the suggestion made by researchers that were aware of our preliminary results.

In short, the present study evidenced a lower iron absorption in rats fed with fortified whole cow's milk containing the same type and quantity of iron as infant formula. Therefore, we demonstrated the great relevance of the early nutritional intervention in those children who are not breastfed and who consume whole cow's milk with the purpose of avoiding iron deficiency and its systemic consequences. In conclusion, we would like to mention that the experimental model used in the present study was appropriate to assess the interaction between the nutrients of different nutritional interventions and their effects on body iron levels, without significantly impairing the growth of those animals fed with liquid diet.

\section{References}

1. World Health Organization, United Nations University, United Nations Children's Fund. Iron deficiency anaemia: assessment, prevention, and control. A guide for programme managers. Geneva: WHO; 2001. http://www.who.int/reproductive-health/ docs/anaemia.pdf. Access: 31.08.2008

2. Brasil. Ministério da Saúde. Secretaria de Ciência, Tecnologia e Insumos Estratégicos. Departamento de Ciência e Tecnologia. PNDS 2006. Pesquisa nacional de demografia e saúde da criança e da mulher. Brasília (DF): Ministério da Saúde; 2008. http:// bvsms.saude.gov.br/bvs/pnds/img/relatorio_final_pnds2006.pdf. Access: 31.08 .2008 .

3. American Academy of Pediatrics Committee on Nutrition: The use of whole cow's milk in infancy. Pediatrics. 1992;89:1105-9.

4. Assis AM, Gaudenzi EN, Gomes G, Ribeiro RdeC, Szarfac SC, Souza SB. Hemoglobin concentration, breastfeeding and complementary feeding in the first year of life. Rev Saude Publica. 2004;38:543-51.

5. Nogueira CS, Colli C, Silverio Amâncio OM. Infant formula iron dialysability related to other nutrients. Food Chem. 2005;90:779-83.

6. Hallberg L, Brune M, Erlandsson M, Sandberg AS, Rossander-Hultén L. Calcium: effect of different amounts on nonheme-and hemeiron absorption in humans. Am J Clin Nutr. 1991;53:112-9.

7. Deehr MS, Dallal GE, Smith KT, Taulbee JD, Dawson-Hughes. Effects of different calcium sources on iron absorption in postmenopausal women. Am J Clin Nutr. 1990;51:95-9.
8. Cook JD, Dassenko SA, Whittaker P. Calcium supplementation: effect on iron absorption. Am J Clin Nutr. 1991;53:106-11.

9. Hallberg $B L$, Rossander-Hulthén $L$, Brune $M$, Gleerup $A$. Inhibition of haem-iron absorption in man by calcium. $\mathrm{Br}$ J Nutr. 1992;69:533-40.

10. Hurrel RF, Lynch SR, Trinidad TP, Dassenko SA, Cook JD. Iron absorption in humans as influenced by bovine milk proteins. Am J Clin Nutr. 1989; 49: 546-52.

11. Sarriá B, Vaquero MP. Zinc and iron bioavailability in a powder or in-bottle-sterilized infant formula estimated by in vitro and in suckling rats. J Nutr Biochem. 2001;12;266-73.

12. Drago SR, Valencia ME. Influence of components of infant formulas on in vitro iron, zinc, and calcium availability. J Agric Food Chem. 2004;52:3202-7.

13. Bosscher D, Van Caillie-Bertrand M, Robberecht H, Van Dyck K, Van Cauwenbergh $\mathrm{R}$, Deelstra H. In vitro availability of calcium, iron, and zinc from first-age infant formulae and human milk. J Pediatr Gastroenterol Nutr. 2001;32:54-8.

14. Jovani M, Barbera R, Farre R, Martin de Aguilera E. Calcium, iron, and zinc uptake from digests of infant formulas by Caco-2 cells. J Agric Food Chem. 2001;49:3480-5.

15. Hurrell RF, Davidsson L, Reddy M, Kastenmayer P. A comparison of iron absorption in adults and infants consuming identical infant formulas. Br J Nutr. 1998; 79:31-6.

16. Sarriá B, Vaquero MP. Iron bioavailability from powdered and in-bottle-sterilized infant formulas in suckling and weanling rats. Nutrition. 2004;20:788-93.

17. Wintrobe $M$, Mollin D, Hebert V, Blanc B, Finch $C$, Halberg $L$ et al. Anemias nutricionales. Geneva: Organizacion Mundial de la Salud; 1968.

18. Coudray C, Tressol JC, Gueux E, Rayssiguier Y. Effects of inulintype fructans of different chain length and type of branching on intestinal absorption and balance of calcium and magnesium in rats. Eur J Nutr. 2003;42:91-8.

19. Leshner AI, Litwin VA, Squibb RL. A simple method for carcass analysis. Physiol Behav. 1972;9:281-2.

20. Folch J, Lees M, Sloane Stanley GH. A simple method for the isolation and purification of total lipides from animal tissues. J Biol Chem. 1957;226:497-509.

21. Cook JD, Reddy M. Effect of ascorbic acid intake on nonheme-iron absorption from a complete diet. Am J Clin Nutr. 2001;73:93-8.

22. Leong WI, Bowlus CL, Tallkvist J, Lönnerdal B. Iron supplementation during infancy-effects on expression of iron transporters, iron absorption, and iron utilization in rat pups. Am J Clin Nutr. 2003;78:1203-11.

23. Schmidt IM, Damgaard IN, Boisen KA, Mau C, Chellakooty M, Olgaard $\mathrm{K}$, et al. Increased kidney growth in formula-fed versus breast-fed healthy infants. Pediatr Nephrol. 2004;19:1137-44.

24. Jakobsson B, Celsi G, Lindblad BS, Aperia A. Influence of different protein intake on renal growth in young rats. Acta Paediatr Scand. 1987; 76:293-9.

25. Fernandes SM, de Morais MB, Amâncio OM. Intestinal blood loss as an aggravating factor of iron deficiency in infants aged 9 to 12 months fed whole cow's milk. J Clin Gastroenterol. $2008 ; 42: 152-6$

\section{Correspondence:}

Mauro Batista de Morais

Rua Pedro de Toledo no 441/443 - Vila Clementino

CEP 04039-031 - São Paulo, SP - Brazil

Tel. : +55 (11) 5579.5834

Fax: +55 (11) 5579.5834

E-mail: mbmorais@osite.com.br 